\begin{tabular}{|l|l|l||}
\hline \multicolumn{2}{|c|}{ PublisherInfo } \\
\hline \hline PublisherName & $:$ & BioMed Central \\
\hline \hline PublisherLocation & $:$ & London \\
\hline \hline PublisherImprintName & $:$ & BioMed Central \\
\hline \hline
\end{tabular}

\title{
Does quality of life affect outcome?
}

\begin{tabular}{||l|l|l||}
\hline \multicolumn{2}{|c||}{ ArticleInfo } \\
\hline \hline ArticleID & $:$ & 4319 \\
\hline \hline ArticleDOI & $:$ & $10.1186 /$ ccf-2001-73602 \\
\hline \hline ArticleCitationID & $:$ & 73602 \\
\hline \hline ArticleSequenceNumber & $:$ & 30 \\
\hline \hline ArticleCategory & $:$ & Paper Report \\
\hline \hline ArticleFirstPage & $:$ & 1 \\
\hline \hline ArticleLastPage & $:$ & 3 \\
\hline \hline & & RegistrationDate : 2001-12-5 \\
ArticleHistory & $:$ & Received \\
\hline ArticleCopyright & $:$ & Biomed Central Ltd2001-10-29 \\
\hline \hline ArticleGrants & $:$ & \\
\hline \hline ArticleContext & $:$ & 1305455 \\
\hline \hline
\end{tabular}


Jeremy Bewley, Affl

Aff1 Bristol, UK

Keywords

Quality of life, intensive care, outcome assessment, severity of illness inde

\section{Context}

Clinicians frequently use quality of life (QOL) assessments when determining the merits of intensive care admission for a patient. However, analysis of QOL in ICU patients-especially before ICU admission-has received little attention. This is probably because such studies are difficult to undertake, as, when patients are unable to complete questionnaires themselves, QOL assessments are dependent on surrogates who may be unreliable. This study aims to assess the influence of pre ICU admission QOL on resource utilisation and mortality rate, by using a QOL score.

\section{Significant findings}

Of the patients admitted, 33\% had a normal QOL score. Poor pre-ICU QOL correlated significantly with increasing age, APACHE III score, and hospital mortality but there was no correlation with length of ICU stay or therapy intervention scoring system (TISS) score on multivariate analysis. When the preICU QOL was added as a variable to the APACHE III model the receiver operating curve characteristic increased from 0.83 to 0.834 .

\section{Comments}

QOL questionnaires can be unreliable, particularly when used by surrogates for assessing aspects of mental health-while aspects of chronic medical health are already included in the APACHE III score. Based on unchanged lengths of ICU stay and admission TISS scores the authors conclude that pre-ICU quality of life has little influence on resource utilisation. Unfortunately there are no data on hospital length of stay and there is no attempt to correct the ICU length of stay data for the higher mortality in those patients with a poor quality of life. Furthermore, there is no attempt to calculate resources used per survivor, despite mortality increasing from $17.3 \%$ to $38.6 \%$ as premorbid QOL deteriorated. Future 
study should be focused on those patients who are refused admission on the basis of a poor premorbid QOL.

\section{Methods}

This is an observational prospective multicentre study of 8685 patients admitted to 85 Spanish ICU's between 1992 and 1993. In addition to routine data collection, the patient or surrogate completed a quality of life questionnaire. The scores from these questionnaires were then compared with other data including APACHE III, TISS, age, ICU length of stay, and ICU mortality.

\section{Additional information}

\section{References}

1. Rivera-Fernandez R, Sanchez-Cruz JJ, Abizanda-Campos R and Vazquez-Mata G: Quality of life before intensive care unit admission and its influence on resource utilisation and mortality rate . Crit Care Med. 2001, 29: 1701-1709. 